\title{
A Study on Visceral Abnormalities during Cadaveric Dissection
}

\author{
Dr Sarita Behera ${ }^{1}$, Dr Bijaya Kumar Dutta ${ }^{2}$,Dr Mamata Sar $^{3}$ \\ Department of Anatomy \\ V.S.S.Medcal College, Burla, Sambalpur, Odisha, India
}

\begin{abstract}
During routine dissection classes of first MBBS students, variations in different viscera are observed frequently. The present study was undertaken to highlight these salient features so as to improve the knowledge of anatomists and enable them to explain these variations to surgeons and radiologists .32 formalin preserved adult cadavers used for routine dissection from the year 2009-10 to 2012-13 were included in the study. Various visceral abnormalities were noted. The embryological basis and clinical significance were studied. During these four years we came across variations in lungs, kidney, liver and thyroid gland in the form of presence of accessory fissures in right lung (3 cases), abnormal position of hilum of kidney (2 cases), rudimentary left lobe of liver ( 1 case) and absence of isthmus of thyroid gland (1 case).This study will be helpful for the clinicians in planning and executing surgical and radiological interventions.
\end{abstract}

Key Words:Visceral abnormality, Accessory fissure, Hilum of kidney, Isthmus of thyroid gland.

\section{INTRODUCTION}

During routine dissection classes, very often we come across different variations. About vessels, muscles and nerves many authors have studied earlier. But about the variations of different viscera not much has been studied .Keeping this in view, the present study was undertaken to highlight these salient features so as to improve the knowledge of the anatomists and enable them to explain these variations to surgeons and radiologists.

\section{MATERIALS \& METHODS}

32 formalin preserved adult cadavers used for routine dissection from the year 2009-10 to 2012-13 were included in the study. The abnormalities were recorded and were tabulated. The embryological basis of each variation was studied and was correlated with study by other authors.

\section{OBSERVATION}

During these 4 years, we came across abnormalities of Lungs,Liver,Kidney and Thyroid gland in the form of presence of accessory fissures in right lung ( 3 cases), abnormal position of hilum of kidney( 2 cases), rudimentary left lobe of liver (1 case) and absence of isthmus of thyroid gland( 1 case)

\section{Presence of accessory fissure in right Lung}

We observed 3 cases of right lungs where an accessory fissure was extending horizontally backwards from the oblique fissure at mid axillary line towards the vertebral part of medial surface. In the $1^{\text {st }}$ and 3 rd case, this accessory fissure was not meeting the normal horizontal fissure, where as in the $2^{\text {nd }}$ case it was meeting. This accessory fissure separated the lower lobe into a superior and an inferior segment.
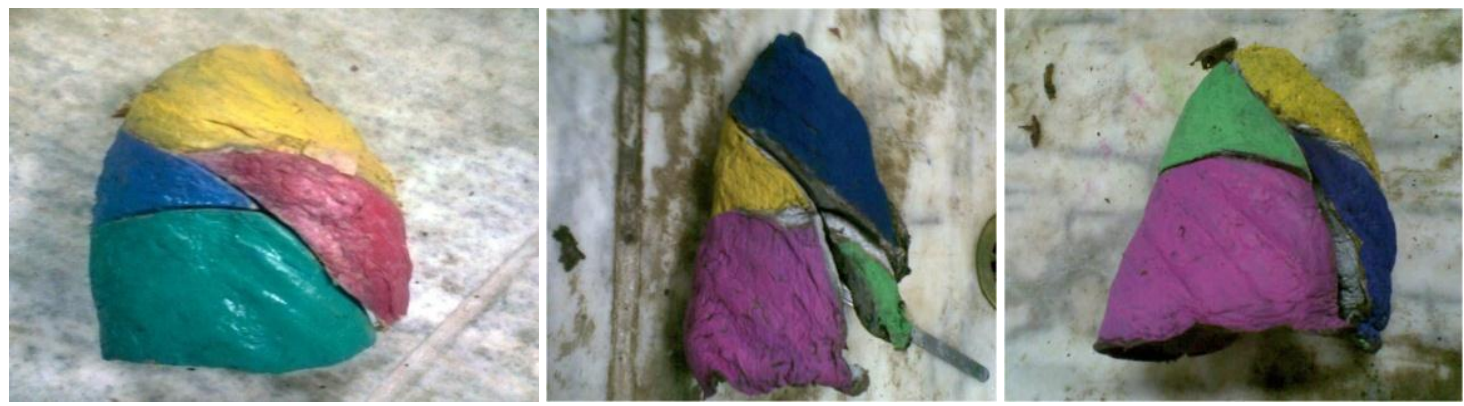

Figure 1: Photographs showing accessory fissures of Right Lungs in three different cases

\section{Abnormal position of hilum of kidney}

We found two cases where hilum of kidney was present either anteriorly or at the upper pole instead of normal position in the medial border. In the first case it was present anteriorly in the left kidney.In $2^{\text {nd }}$ case It 
was present at the upper pole of right kidney and all the structures (Ureter, Renal Artery, Renal Vein) were leading to the kidney through it.

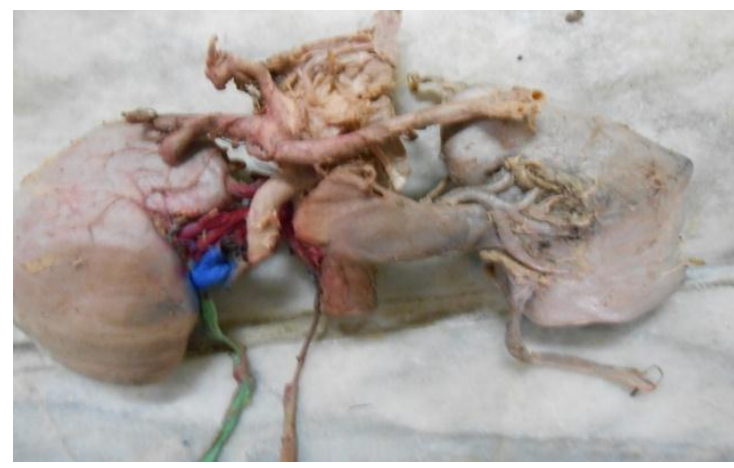

Figure-2: Photograph showing anteriorly placed hilum of left kidney.

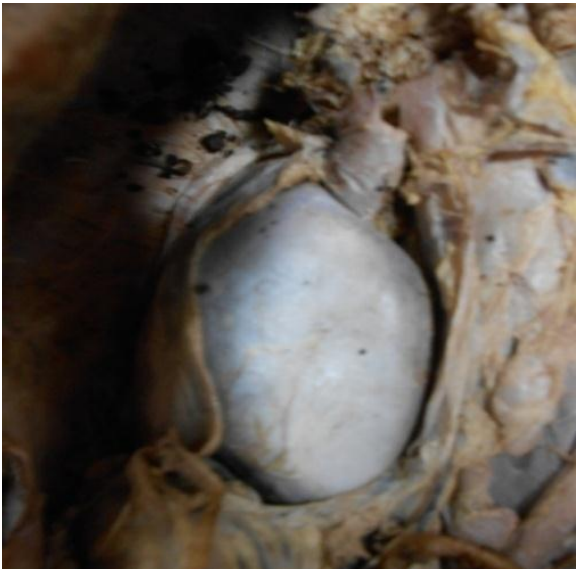

Figure-3: Photograph showing hilum of right kidney at upper pole (Anterior view)

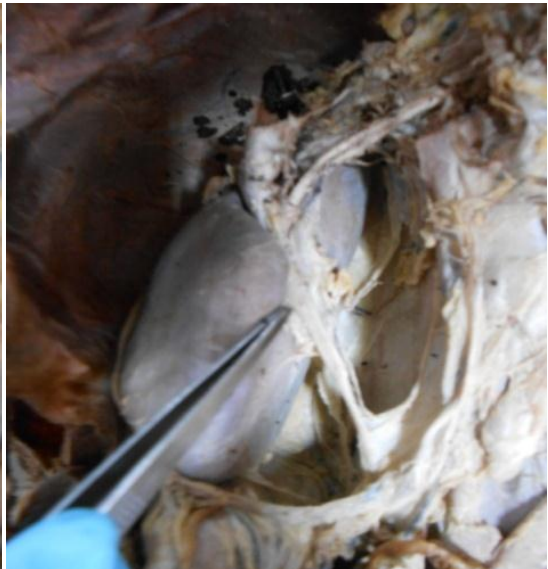

Figure-4 Photograph showing hilum of right kidney at upper pole(Posterior view)

\section{Rudimentary left lobe of liver}

We found an interesting case of liver where the left lobe was almost absent.The falciform ligament was attached to the extreme left margin. When viewed from the inferior aspect ligamentum teres was found to be attached somewhat to the right making the left lobe rudimentary. Caudate lobe, quadrate lobe and gall bladder were normal.

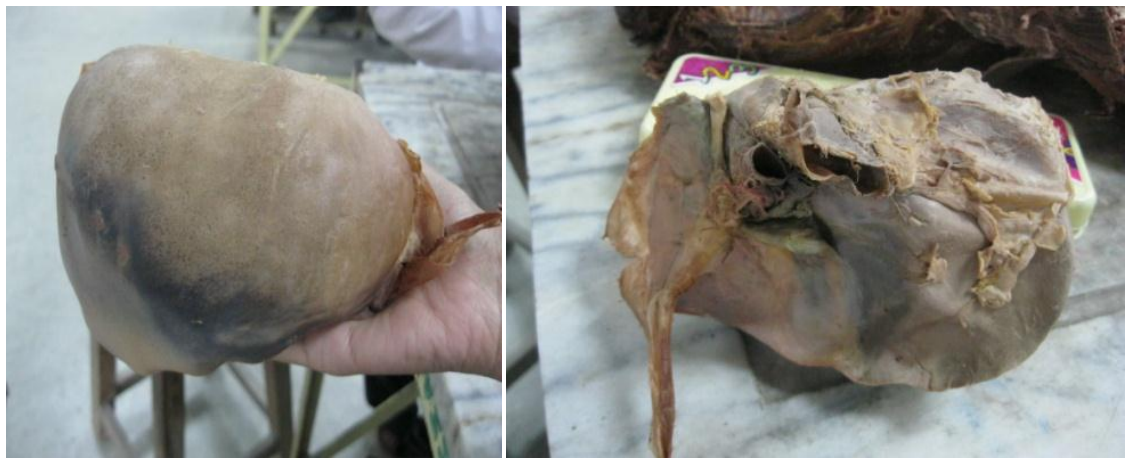

Figure-5: Photograph showing rudimentary left lobe of liver

\section{(Anterior view)}

Figure-5: Photograph showing rudimentary left lobe of liver

\section{Absence of Isthmus of Thyroid gland}

(Posterior view)

We observed a case where the isthmus of thyroid gland was absent..The position and extent of the lateral lobes were normal. 


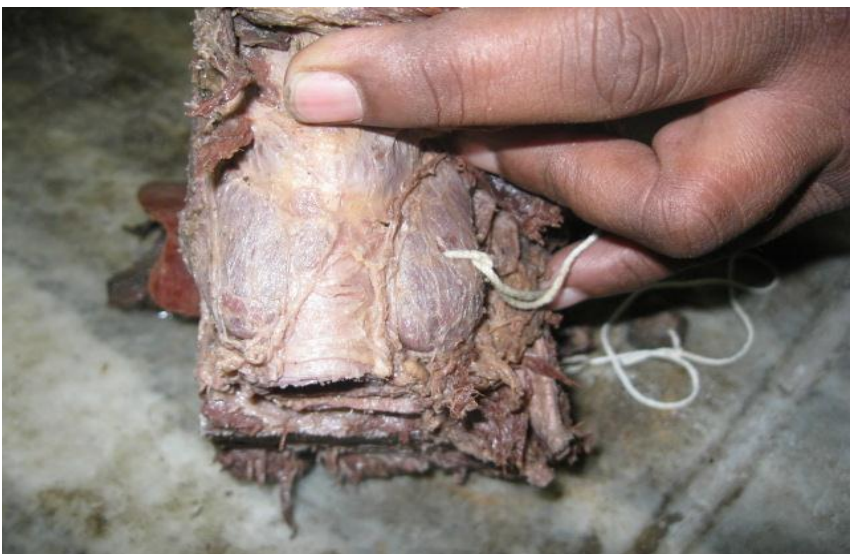

Figure 7- Photograph showing absence of isthmus of thyroid gland

\section{RESULTS:}

The observations were tabulated in the following tables.

Table-1Incidence of Visceral Variations

\begin{tabular}{|l|l|l|}
\hline No of Cadavers & $\begin{array}{l}\text { No of Visceral } \\
\text { variation }\end{array}$ & Incidence (\%) \\
\hline 32 & 07 & 21.8 \\
\hline
\end{tabular}

TABLE-2

Incidence of Variation in Different Viscera

\begin{tabular}{|l|l|l|}
\hline Name of the viscera & $\begin{array}{l}\text { Number of } \\
\text { Variation }\end{array}$ & $\begin{array}{l}\text { Percentage } \\
(\mathbf{n = 3 2})\end{array}$ \\
\hline Lungs & 3 & 9.3 \\
\hline Liver & 1 & 3.1 \\
\hline Kidney & 2 & 6.2 \\
\hline Thyroid gland & 1 & 3.1 \\
\hline
\end{tabular}

TABLE-3Sex Distribution

\begin{tabular}{|l|l|l|l|l|}
\hline Type of variation & No of Males & $\begin{array}{l}\text { Percentage } \\
(\mathbf{n = 3 2})\end{array}$ & No of females & $\begin{array}{l}\text { Percentage } \\
(\mathbf{n}=\mathbf{3 2})\end{array}$ \\
\hline Accessory fissure of lungs & 2 & 6.2 & 1 & 3.1 \\
\hline Rudimentary left lobe of liver & 0 & 0 & 1 & 3.1 \\
\hline $\begin{array}{l}\text { Anteriorly placed hilum of } \\
\text { kidney }\end{array}$ & 0 & 0 & 1 & 3.1 \\
\hline Hilum at upper pole of kidney & 0 & 0 & 1 & 3.1 \\
\hline Agenesis of isthmus of thyroid & 1 & 3.1 & 0 & 0 \\
\hline
\end{tabular}

\section{DISCUSSION}

Nonobliteration of some of the spaces which are present between the bronchopulmonary segments in foetal life (excepting those two which give rise to horizontal and oblique fissures) is responsible for the presence of accessory fissures [1]. Accessory fissures like azygos fissure, superior and inferior accessory fissures have been reported earlier by many authors [2].Incidence of superior accessory fissure is reported to be more common in right lung as compared to left one which is consistent with our study [3].We found the incidence of superior accessory fissure to be $9.3 \%$ in our study where as other autopsy studies found it to be 5-30\% and high resolution CT scan detects it to be $3 \%$ [3].

Up to $3^{\text {rd }}$ month of intrauterine life both the lobes of liver are of equal in size. After that, as the haemopoetic function is assumed by the spleen \& bone marrow, the left lobe regresses. Excessive regression might have lead to this rudimentary left lobe in the present case. Incidence of absent or rudimentary liver lobes have earlier been reported to be $1.85 \%$ where as we found it to be $3.1 \%$ [4].Further, earlier studies reveal that 
the left lobe is commonly involved so is the result in our study [4].The defect was seen in a female cadaver in contrast to others where male predominance was found [4].

During developmental rotation of kidney, the hilum shifts to its medial border from its anterior position. Non rotation or malrotation leads to the abnormal position of the hilum. Muttarak et al in their imaging study detected 4 cases of malrotation ( 2 non rotation and 2 reverse rotation)[5].We found 1 case of non rotation making the hilum anterior in position and 1 case where hilum is present at the upper pole .It is difficult to explain what may have lead to this position of hilum at upper pole.

During the development of thyroid gland, the thyroglossal duct grows caudally and bifurcates to give rise to the thyroid lobes and the isthmus. A high division of the thyroglossal duct can generate two independent thyroid lobes with the absence of isthmus. Incidence of agenesis of the thyroid isthmus has been reported to vary from $5 \%$ to $10 \%$ by Pastor et al, $8 \%$ to $10 \%$, by Marshall, $14.6 \%$,by Dixit et al and33\% by Ranade et al $[6,7,8,9]$. In our study we found it to be little low i.e. $3.1 \%$.

Though the congenital malformations of heart are very common, we could not find any of them. This may be due to the fact that most of them are not compatible with life and as we were studying the adult cadavers, we did not come across them.

\section{CONCLUSION}

Knowledge of these variations will be helpful for the clinicians, mostly surgeons and radiologists.Presence of an accessory fissure in lungs may act as a barrier to spread of infection, creating a sharply marginated pneumonia which can wrongly be interpretated as atelectasis or consolidation [3].They may mislead the radiological findings. Identification of completeness of fissure is important prior to lobectomy; because individuals with incomplete fissures are more prone to develop postoperative air leak [10, 11].Prior awareness of abnormal position of hilum of kidney is very important for different renal surgeries..In planning biliary surgery or a portosystemic anastomosis, knowledge of abnormalities of lobes of liver is quite helpful for the surgeons. Agenesis of isthmus of thyroid gland can be associated with other types of dysorganogenesis, such as the absence of a lobe or the presence of ectopic thyroid tissue and hence in clinical practice when such a condition is diagnosed, it is necessary to perform a differential diagnosis against other pathologies such as autonomous thyroid nodule or thyroiditis [8].This study will definitely be helpful for the clinicians in planning and executing surgical and radiological interventions and also will be of great academic interest to all medical personnel.

\section{REFERENCES}

[1]. Meenakshi S, Manjunath KY, Balasubramanyam V: Morphological Variations of the Lung Fissures and lobes. Indian J. of Chest Dis Allied Sci. 2004 Jul-Sep; 46(3):179-82.

[2]. Standring S, Borley NR, Collins P et al.Gray’s Anatomy-: The Anatomical Basis of Clinical Practice-Pleura, lungs, trachea and bronchi.40th ed.Spain: Churchill Livingstone; 2008: 993.

[3]. Godwin JD, Tarver RD: Accessory Fissures of the Lung. AJR Am J Roentgenol. 1985 Jan; 144(1):39-47.

[4]. Aktan, ZA., Savas, R., Pinar Y, Arslan, O et al. Lobe and Segment Anomalies Of the Liver.Anat. Soc. India 50(1) 15-16 (2001)

[5]. Muttarak M, SriburiT : Congenital renal anomalies detected in adulthood. Biomed Imaging Interv J 2012; 8(1):e7.

[6]. Pastor VJF, Gil VJA, De Paz Fernández FJ, Cachorro MB.: Agenesis of the thyroid isthmus. Eur J Anat. 2006; 10:83-84.

[7]. Marshall CF. Variations in the form of the thyroid gland in man. J Anat Physiol. 1895 Jan; 29(Pt 2):234-9.

[8]. Dixit D, Shilpa MB, Harsh MP, Ravishankar MV: Agenesis of isthmus of thyroid gland in adult human cadavers: a case series.Cases J. 2009 Apr 20; 2:6640.

[9]. 9.Ranade AV, Rai R, Pai MM, Nayak SR, Prakash, Krishnamurthy A, Narayana S. Anatomical variation of the thyroid gland: possible surgical implications. Singapore Med J. 2008 Oct; 49(10):831-4.

[10]. Craig SR, Walker WS: A proposed anatomical classification of the pulmonary fissures.J R Coll Surg Edinb 1997 Aug; 42 (4):233-4.

[11]. 11.Venuta F, Rendina EA, De Giacomo T, Flaishman I, Guarino E, Ciccone AM, Ricci C:1998 Technique to reduce air leaks after pulmonary lobectomy. Eur J Cardiothorac Surg. 1998 Apr; 13(4):361-4. 